\title{
CONFLICTOS TRÁGICOS Y DERECHO. POSIBLES DESAFÍOS
}

\author{
Guillermo Lariguet ${ }^{1}$ \\ CONICET, Argentina
}

\begin{abstract}
RESumen. Mi propósito para este trabajo consiste en ofrecer una caracterización general de 'conflicto trágico' en el dominio de los valores o principios morales o jurídicos. En efecto, quiero explorar algunos de los principales desafíos que los juristas deben analizar si se admitiese la existencia de una clase especial de conflicto normativo: los conflictos trágicos.

Dividiré este trabajo de la siguiente manera. Primero, mostraré los más importantes desacuerdos que los filósofos mantienen acerca de la naturaleza de la categoría "conflicto trágico". Segundo, expondré en términos generales algunos de los principales desafíos que los conflictos trágicos opondrían al derecho. Finalmente, sugeriré algunos problemas relacionados a los límites de la racionalidad jurídica, exponiendo sus principales consecuencias filosóficas.
\end{abstract}

\begin{abstract}
My purpose for this work is to offer a general characterization of the category of 'tragic conflict' in the domain of legal or moral values or principles. I want to explore some of the main challenges that lawyers must analyze if they admit the existence of an special class of normative conflicts: tragic conflicts. I will divide this work in the following manner. First, I will show the most important disagreements that philosophers maintain about the nature of the category "tragic conflict". Second, I will expound in general terms some of the principal challenges that tragic conflicts would oppose to the law. Finally, I will suggest some problems related to the limits of legal rationality, showing its main philosophical consequences.
\end{abstract}

\footnotetext{
${ }^{1}$ Conicet, CIFFYH, Universidad Nacional de Córdoba, Argentina. Quiero agradecer especialmente a Rodrigo Sánchez Brígido por las observaciones que hiciera a una versión previa de este trabajo. También discutí este trabajo en el Seminario de Filosofía del Derecho que dirige el Profesor Ricardo Caracciolo en la Universidad Nacional de Córdoba. En este sentido, debo mucho a las observaciones de Caracciolo, Juan Iosa, Celia Abril, Federico Arenas, María del Carmen Cerutti y Paula Gaido.
} 
"Las tragedias terminan mal. El personaje trágico es destruido por fuerzas que no pueden ser entendidas del todo ni derrotadas por la prudencia racional. Cuando las causas del desastre son temporales, cuando el conflicto puede ser resuelto con medios técnicos o sociales, entonces podemos contar con teatro dramático, pero no con la tragedia. Leyes de divorcio más flexibles no podrían modificar el destino de Agamenón; la psiquiatría social no es respuesta para Edipo. Pero las relaciones económicas más sensatas o mejores sistemas de cañerías pueden resolver algunas de las graves crisis que hay en los dramas de Ibsen. Conviene tener bien presente esta distinción. La tragedia es irreparable. No puede llevar a una compensación justa y material por lo padecido. Al final Job recibe el doble de asnas; y así tenía que ser, pues Dios había representado con él una parábola de la justicia. A Edipo no le devuelven la vista ni el cetro tebano. El teatro trágico nos afirma que las esferas de la razón, el orden y la justicia son terriblemente limitadas y que ningún progreso científico o técnico extenderá sus dominios. ${ }^{2}$

\section{Introducción}

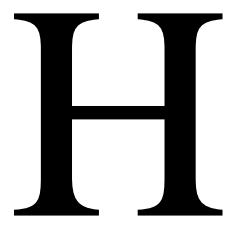

ay conflictos de valores que se consideran trágicos. En la literatura de filosofía moral se los conoce con el nombre de "dilemas morales"3. Aunque todavía no resulta del todo claro cuándo un conflicto es "genuinamente” trágico, suele aceptarse que tal cosa ocurre cuando: i) el conflicto no tiene

\footnotetext{
${ }^{2}$ Steiner, George: La Muerte de la Tragedia, Traducción de E.L.Revol, Monte Ávila Editores, Barcelona, 2001, pp. 12-13.

${ }^{3} \mathrm{Al}$ igual que filósofos como Bernard Williams, en el contexto de este trabajo, emplearé las expresiones 'conflictos trágicos', 'casos trágicos' y 'dilemas morales' de manera indistinta. No pretendo suscitar debate conceptual con este uso sino, más bien, poner en evidencia los lazos entre dos tradiciones discernibles: la literaria y la filosófica. Pienso que los literatos, particularmente los trágicos (los griegos, los del período isabelino, etc..) intuyeron, pusieron en escena y plantearon los principales problemas y 'soluciones' a la cuestión de los dilemas morales. Los trágicos griegos (Esquilo, Sófocles, Eurípides) y los isabelinos (emblemáticamente Shakespeare) presentaron la más amplia fenomenología moral de situaciones que los filósofos acostumbran a tratar conceptualmente a partir del término 'dilemas morales'. Con otras palabras, mientras los trágicos desarrollaron sus intuiciones con instrumentos metafóricos o alegóricos, los filósofos desarrollaron investigaciones conceptuales con el propósito de reconstruir los problemas filosóficos subyacentes a dichas intuiciones. Por cierto que mi pretensión de no suscitar debate conceptual con el mencionado uso no erradica la posibilidad de que tal debate surja. Por ejemplo, hay filósofos que podrían sostener que, tras la caracterización de un dilema moral como un caso de "conflicto trágico" se postula la tesis del "mal inevitable" o de la "consecuencia trágica"; tesis que subyace al planteo de Agamenón cuando, interrogándose a sí mismo, expresa “¿cuál de estos caminos estará libre de males?”. En efecto, filósofos como David Martínez Zorrilla plantean que la tesis del mal inevitable o de la consecuencia trágica tiene solo una conexión "contingente" con los dilemas morales porque podría haber situaciones dilemáticas que no tengan estas consecuencias. Bien puede decirse que una posición como la de David me enfrenta a algo que no quiero suscitar: un debate conceptual. Si éste fuera el caso, no es éste el lugar para intentar saldarlo. Pero si tuviese que entrar a este debate, cosa que no quiero hacer aquí pues solo planteo las cosas en término de un uso indistinto
} 
resolución racional posible $e^{4}$, por ejemplo porque los valores o principios contendores son considerados mutuamente inderrotables ${ }^{5}$ o incomparables ${ }^{6}$ o ii) el conflicto podría ser resuelto eligiendo uno de los principios, pero esta elección entrañaría sacrificio o pérdida moral.

El punto es que si hay conflictos trágicos genuinos se podría activar una tesis en virtud de la cual se sostenga el carácter limitado de la racionalidad ${ }^{7}$ y, para el caso concreto del derecho, lo que podría denominarse como el carácter limitado de la "racionalidad jurídica".

Precisamente, en Juicios Salomónicos, Jon Elster entiende que la racionalidad tiene "límites", entre otras cosas, cuando "la razón no nos dice qué hacer en ciertos casos”. . Elster examina varias hipótesis que explican esta incapacidad de la razón: por ejemplo, problemas de indeterminación e inconmensurabilidad. Elster mantiene algo importante y es lo siguiente: que, pese a que la tesis pueda parecer irremediablemente obvia, no lo es en cuanto se advierte la reticencia expresa o tácita de la mayoría de los filósofos a

de las expresiones “dilema moral” y “conflicto trágico”, lo que diría es lo siguiente: estoy de acuerdo con la observación de David pero esto no liquida todavía un punto que yo exploro en este trabajo y es el siguiente: que los dilemas que tiene en mente David aun si involucran problemas morales no son “trágicos”. Desde luego, yo estoy interesado en esta última posibilidad. Sobre la cuestión véase Martínez Zorrilla, David: “Conflictos Constitucionales, Ponderación e Indeterminación Normativa”, Tesis Doctoral, Versión Manuscrita, ps. 348 y ss.

${ }^{4}$ Por 'resolución racional' entiendo una solución que pueda ser sometida a algún test de control racional. Como se sabe, los test de control racional varían según el tipo de teoría que se ofrezca. Aquí no necesito comprometerme con ninguna teoría en especial.

${ }^{5}$ McConnell, Terrance: “Moral Dilemmas”, en Stanford Encyclopaedia of Philosophy, p. 2. (se encuentra en internet).

${ }^{6}$ Véase Gowans, Christopher: “Introduction. The Debate on Moral Dilemmas”, en Moral Dilemmas, edited by Christopher. W. Gowans, Oxford University Press, Oxford, 1987, pp. 25, 29-30.

${ }^{7}$ Aquí no necesito comprometerme con ninguna tesis acerca del carácter unitario o fragmentario de la razón práctica en general ni con alguna versión específica de la deliberación racional ni con alguna teoría específica de la racionalidad jurídica.

${ }^{8}$ Por 'racionalidad jurídica' entiendo cualquier conjunto de argumentos que satisfaga, cuando menos, dos condiciones: ser considerados jurídicos -conforme a algún criterio determinado- y susceptibles de algún tipo de control racional; el “contenido" de ambas condiciones depende, a su vez, de qué teoría de la racionalidad del derecho y de la argumentación jurídica se adopte. Aquí no defiendo ninguna teoría específica sobre la racionalidad del derecho y la argumentación jurídica. Para una referencia a este tipo de cuestiones véase Atienza, Manuel: “Los límites de la interpretación constitucional”. De nuevo sobre los casos trágicos, en Interpretación jurídica y decisión judicial, Rodolfo Vázquez Compilador, Doctrina Jurídica Contemporánea, Fontamara, México, 2002.

${ }^{9}$ Elster, Jon: Juicios Salomónicos.Las limitaciones de la racionalidad como principio de decisión, Traducción de Carlos Gardini, Gedisa, Barcelona, 1995, p. 9. 
admitir algo así. Sin embargo, no admitir la naturaleza limitada de la razón, le parece a Elster, un compromiso con la irracionalidad. ${ }^{10}$

A pesar de que la tesis de Elster pueda ser nítida, ella no es irrefutable $e^{11}$.

Muchos filósofos han desarrollado argumentos diversos e interesantes para mostrar porqué los dilemas morales "genuinos" no existen, son productos de ficción ${ }^{12}$, y por tanto no desafían la racionalidad.

En el caso del derecho resulta ya casi un lugar común traer a Ronald Dworkin como un campeón que puede poner en aprietos la tesis mencionada. Como se sabe, Dworkin piensa que hay una sola respuesta correcta en casos difíciles, aun si esto no puede ser demostrado. Incluso en un artículo reciente, donde discute ideas de Isaiah Berlin que apoyan la existencia de conflictos trágicos, él ha sostenido que esto no es así si uno puede emplear otra concepción de los valores y sus relaciones. ${ }^{13}$

En el presente trabajo intento contrarrestar una cierta tendencia de la filosofía jurídica a olvidar el problema de los conflictos trágicos ${ }^{14}$. Particularmente me interesa explorar algunos de los principales desafíos que tendría que enfrentar el derecho si se aceptara que existen conflictos trágicos genuinos.

${ }^{10}$ Elster, Jon: Juicios Salomónicos.Las limitaciones de la racionalidad como principio de decisión, op.cit, p. 9.

${ }^{11}$ No me parece trivial recordar que un argumento que logre refutar una tesis filosófica -en caso que esto fuera posible- es relativo a una manera de concebir la argumentación racional, los argumentos compelentes y la refutación. Sin pretensiones de exhaustividad y solo a modo de ejemplo recuérdese que lo que es “compelente”, "racional” y "refutativo” en los Diálogos de Platón cambia considerablemente en la República que es donde Platón sugiere la necesidad de una "teoría de las formas" (eidética) que proporcione una base "imparcial” para resolver "racionalmente” cuál es la mejor forma de concebir la naturaleza de la argumentación, su importancia para la deliberación práctica y la obtención de acciones concretas. Si Platón logró diseñar una base así es algo que es motivo de una discusión que no necesito revisar aquí. Pero repárese que esta "tradición” que inicia Platón -en franca oposición a una manera de argumentar que los sofistas desarrollan y cuya desarticulación o intentos de desarticulación Platón inicia en el Gorgias- es reformulada por Aristóteles a partir de una concepción teleológica de la vida y una teoría de las virtudes.

${ }^{12}$ Hare, Richard: “Cómo resolver los problemas morales racionalmente”, en Racionalidad. Ensayos sobre la racionalidad en ética y política, ciencia y tecnología, León Olivé (Compilador), Siglo XXI Editores, México, 1988, p. 69.

${ }^{13}$ Dworkin, Ronald: “Do Liberal Values Conflict?”, en The Legacy of Isaiah Berlin, Edited by Ronald Dworkin, Mark Lilla and Robert. B. Silvers, New York Review Books, 2001, especialmente pp.83-85. También hay muchas sugerencias de Dworkin acerca de cómo concebir los conceptos referidos a valores y sus relaciones en "Hart's Postscript and the Character of Political Philosophy”, Oxford Journal of Legal Studies, Vol. 24, Nº.1, 2004, pp. 1-37.

${ }^{14}$ Tendencia sobre la que ya advirtiera hace algunos años Atienza, Manuel: "Los límites de la interpretación constitucional”. De nuevo sobre los casos trágicos, en Interpretación jurídica y decisión judicial, op. cit., pp. 198-200. 
Dado este interés, mi propósito para este trabajo es modesto en el siguiente sentido: consiste en ofrecer un mapa o lista de carácter general que articule una base para discutir los principales problemas de caracterización de los conflictos trágicos y sus posibles desafíos para el derecho.

En este trabajo procederé como sigue. Primero ofreceré una caracterización general de conflicto trágico, destacando algunos de los principales problemas y desacuerdos a la hora de lograr una caracterización uniforme. Segundo expondré una lista con algunos de los posibles desafíos que entrañaría la aceptación de conflictos trágicos genuinos para un campo como el jurídico. Sobre esta lista vale la pena aclarar dos cosas: primero que ella no intenta ser exhaustiva, pues solo explicita posibles desafíos que considero importantes en función de mis actuales intereses filosóficos; segundo que los desafíos de esta lista solo serán "presentados", su análisis detallado debe ser diferido para un futuro trabajo independiente. Para finalizar sugeriré algunas cuestiones en torno al alcance que podría tener la tesis de los límites de la racionalidad jurídica y expresaré cuáles podrían ser algunas de sus consecuencias posibles.

\section{La caracterización de los conflictos trágicos. Principales problemas}

¿Cuándo un conflicto es trágico? La respuesta a esta pregunta no puede simplemente apoyarse en la explicitación del origen etimológico de la expresión 'tragedia' que, en griego, significa "chivo"15. No puede ser ésta la respuesta a menos que se crea que la etimología es la base para liquidar conceptualmente la cuestión. Esta salida podría incurrir en una falacia adantiquitam que aquí no es necesario cometer.

La respuesta es complicada porque, pese a la profusión bibliográfica reinante en filosofía moral y política, la cuestión dista de ser clara debido a que el núcleo conceptual de la categoría conflicto trágico no está completamente precisado.

En virtud de que el núcleo conceptual de esta categoría no es claro, es que los filósofos desacuerdan en torno a la siguiente cuestión: cuándo un conflicto trágico es "genuino" o meramente "aparente".

\footnotetext{
${ }^{15}$ Hay varias explicaciones posibles para este origen. Para algunos refiere a que el premio -para los poetas trágicos que ganaban una contienda relativa a cuál era la mejor tragedia- era un chivo.

Para otros el "chivo" es una metáfora de lo que es una tragedia: un chivo tiene un frente majestuoso pero sus partes traseras son sucias y desagradables. La metáfora, así, refiere a historias que comienzan maravillosamente y terminan en forma espantosa. Piénsese en Edipo que comienza salvando a Tebas de una peste y es coronado rey, siendo que era hijo -presuntamente- de un pastor de cabras. El fin de Edipo -terrible- es conocido por todos.
} 
Las maneras de enfocar esta cuestión son divergentes. Esto es así por cuanto pareciera que los criterios que emplean los filósofos para identificar un caso trágico son múltiples y dispares. Lo que sigue es un intento de corroboración de mi afirmación

\subsection{Imposibilidad de resolución racional}

Se admite que un conflicto trágico, esto es, un dilema moral, refiere a una situación en que un agente está tironeado por dos valores o principios incompatibles. Un ejemplo ya clásico es el que surge del Existencialismo es un humanismo de Sartre $^{16}$, donde un joven estudiante francés tiene ante sí dos acciones incompatibles: cuidar a su madre o unirse a los aliados en su lucha contra los nazis.

Un rasgo que suele alegarse para sostener que hay conflictos trágicos genuinos es que éstos, a diferencia de los “casos difíciles”, no tienen resolución racional posible. El bloqueo a una resolución racional posible puede explicarse en diversas alternativas. Por ejemplo, porque se reputa que el conflicto es análogo a una situación grave de indeterminación donde no puede aplicarse el principio de bivalencia que controle la verdad o corrección de una respuesta al problema ${ }^{17}$. Por ejemplo, esto podría ocurrir porque se estima que hay valores o principios en conflicto que son inconmensurables. Si son inconmensurables no se puede decir cuál de ellos es mejor o peor y, en consecuencia, quedaría precluida la ponderación como posible método de solución.

En muchas ocasiones, sin embargo, se afirma, en el mismo estilo que Isaiah Berlin ${ }^{18}$, que puede haber una solución del conflicto pero con "sacrificio” o “pérdida moral”.

La idea de que hay "sacrificio” remite al hecho de que la elección por uno de los valores o principios ha dejado algo valioso en el camino: el otro valor o principio dejado a un lado. Siendo así las cosas, la idea de que hay elecciones con sacrificio no el del todo clara porque supone, en el fondo, que la respuesta no es correcta. Precisamente, un núcleo de la categoría de conflicto trágico pareciera vincularse a la idea de que cualquier respuesta al problema no es correcta. Pero, si es así, ¿qué tipo de línea divide la idea de

\footnotetext{
${ }^{16}$ Sartre, Jean Paul: El Existencialismo es un Humanismo, Traducción de Manuel Lamana, Losada, Bs As, 2003, pp. 21-22.

${ }^{17}$ Shafer Landau, Russ: "Ethical Disagreement, Ethical Objectivism and Moral Indeterminacy”, en Philosophy and Phenomenological Research, Vol.LIV, Nº.2, 1994, pp. 332-335. Shafer Landau también examina, con relación a los dilemas morales genuinos, el problema de la inconmensurabilidad. Ver p. 333.

${ }^{18}$ Por ejemplo, en Berlin, Isaiah: “Dos Conceptos de Libertad”, en Cuatro Ensayos sobre la Libertad, versión castellana de Julio Bayón, Alianza Editorial, Madrid, 2003, p. 224.
} 
que no hay respuesta racional posible de la idea de que hay respuesta con sacrificio? La línea o bien es tenue o bien es inexistente desde que podría pensarse que ambas alternativas son descripciones diferentes del mismo problema: la imposibilidad de dar respuestas correctas a ciertos casos.

Por lo pronto, piénsese en que ambas alternativas podrían tener en común dos aspectos: primero, que cualquier cosa que haga el agente se puede ver como incorrecta y, segundo, que lo que hay en un conflicto trágico es elección de un valor o principio en detrimento del otro, un puro acto decisionista. En este último supuesto, se entiende, al menos en una visión estándar ${ }^{19}$, que el hecho de afirmar que solo hay elección, es equivalente con afirmar que no hay base objetiva alguna para dirimir si la elección es correcta. Extrapolando esto al ámbito de los conflictos entre principios constitucionales, esta visión no parece discrepar mucho de la que mantiene un filósofo del derecho como Riccardo Guastini para quien, la "ponderación" entre principios constitucionales en conflicto, no es más que el nombre de una elección por uno de los principios, que produce un sacrificio, y que está montada en el juicio subjetivo de lo que a un juez le parece justo o menos injusto para ese caso $^{20}$. Hasta qué punto el enfoque de Guastini no transforma todo conflicto entre principios constitucionales en un conflicto de tipo trágico es algo que no puedo entrar a considerar aquí.

\subsection{Derrotabilidad vs. inderrotabilidad}

Hegel pensaba que la "tragedia" de un conflicto residía en que cada valor (él hablaba de "sustancias morales") en conflicto tenía, mirado en sí mismo, justificación. ${ }^{21}$ Observando las cosas con el lente de Hegel se podría pensar que, las leyes del estado invocadas en Las Bacantes ${ }^{22}$ por Penteo para

${ }^{19}$ Cuando digo “estándar” me refiero a la visión común según la cual los productos de actos de voluntad son "decisionistas" en un sentido "no racional”. Pero la cuestión dista de ser tan clara porque, después de todo, el enfoque de los actos que son productos de elecciones voluntarias depende de la relación que se establezca entre voluntad y razón. Sobre esto véase Sartori, Giovanni: La Política. Lógica y Método en las Ciencias Sociales, Traducción de Marcos Lara, Fondo de Cultura Económica, México, 2002, pp. 92-93.

${ }^{20}$ Guastini, Riccardo: “Los principios en el derecho positivo”, Distinguiendo. Estudios de teoría y metateoría del derecho, Traducción de Jordi Ferrer i Beltrán, Gedisa, Barcelona, 1999, pp. 167-171.

${ }^{21}$ Ver Hegel, G.W.F: Fenomenología del Espíritu, Traducción de Wenceslao Roces con la colaboración de Ricardo Guerra, Fondo de Cultura Económica, México, 2003, especialmente pp.425-431. Para una explicación de la postura de Hegel y su relación con los intuicionistas británicos véase Gowans, Christopher: "Introduction. The Debate on Moral Dilemmas”, op. cit., pp. 10-12.

${ }^{22}$ Como se sabe, obra de Eurípides. 
repudiar los ritos dionisíacos, están tan justificadas como las leyes divinas invocadas por los que defienden la necesidad de realizar los ritos.

Igualmente, las leyes del estado invocadas por Creonte para negar el derecho a enterrar a un ciudadano considerado traidor a la polis, estarían tan justificadas como las leyes divinas invocadas por Antígona ${ }^{23}$ que respaldarían el derecho a enterrar a su hermano. ${ }^{24}$

Ciertamente aquí hay un enjambre de problemas. ¿Qué significa que cada valor esté justificado? Cuando se señala que ambos están justificados ${ }^{25}$ ¿se está sugiriendo que hay algo así como un empate de valores? Pero, después de todo, ¿son comparables las leyes invocadas de uno y otro lado?

Las preguntas formuladas, si tienen sentido, muestran que la cuestión de cuándo un conflicto trágico es genuino no es clara, pese a la investigación profunda que Hegel realizara sobre el tema.

Aunque Hegel negaba que hubiera, “in the long run”, tragedia debido a que postulaba una suerte de "reconciliación final”" de los valores ${ }^{27}$, uno podría tomar su idea de que cada valor tiene, tomado en sí mismo, justificación.

Que cada valor tenga justificación explica porqué la elección de cualquiera de ellos tornaría no correcta la respuesta y daría sentido a la idea

${ }^{23}$ Para un análisis de cómo la concepción del pre-socrático Anaximandro prefigura la idea de tragedia que Sófocles refleja en Antígona véase Soares, Lucas: Anaximandro y la Tragedia. La proyección de su filosofía en la Antígona de Sófocles, Biblos, Bs As, 2002, especialmente pp. 61-66.

${ }^{24}$ Véase Steiner, George: Antígonas. Una poética y una filosofía de la lectura, Traducción de Alberto Bixio, Gedisa, Barcelona, 1996, p. 31 y ss.

${ }^{25} \mathrm{Al}$ analizar el nacimiento de la tragedia Nietzche señala en un conocido párrafo que “todo lo que existe es justo e injusto, y en ambos casos está igualmente justificado”. Ver Nietzche, Friedrich: El Nacimiento de la Tragedia, Traducción de Andrés Sánchez Pascual, Alianza, Madrid, 2001, p. 98.

${ }^{26}$ La idea de una solución final apunta a que puede haber un estadio de la historia en que los conflictos entre valores sean terminados, disolviendo de esta manera la fragmentación de los valores. Tras esta idea hay un complejo trasfondo metafísico. Los presocráticos, Anaximandro por ejemplo, intuían que la tragedia tenía que ver con la fragmentación de la unidad del cosmos en distintas unidades. Sobre esto véase Soares, Lucas: Anaximandro y la Tragedia. La proyección de su filosofía en la Antígona de Sófocles, op. cit. La intuición del vínculo entre tragedia y fragmentación de valores es destacada por Nietzche en su examen de muchas tragedias que involucran a Dioniso, que era conocido en la antigüedad griega como Zagreo, quien fuera destrozado por los titanes, quedando fragmentado. De esta "fragmentación” hablarían las tragedias en que Dioniso aparece como un protagonista que se lamenta de su fragmentación originaria. Ver Nietzche, Friedrich: El Nacimiento de la Tragedia, op. cit., p. 100 y ss.

${ }^{27}$ Las críticas contemporáneas a la idea de una solución “definitiva” que establezca una unidad armónica de valores tienen como ejemplo paradigmático a Isaiah Berlin. Ver, por ejemplo, Berlin, Isaiah: El Fuste Torcido de la Humanidad. Capítulos de historia de las ideas, Traducción de José Manuel Álvarez Flóres, Edición a cargo de Henry Hardy y Prólogo de Salvador Giner, Ediciones Península, Barcelona, 1998, p. 32. 
de elecciones con sacrificio como las que tiene en mente un filósofo como Isaiah Berlin cuando piensa en los conflictos entre la libertad y la igualdad o Riccardo Guastini cuando piensa en conflictos típicos entre principios constitucionales $^{28}$.

Más técnicamente, filósofos analíticos como Terrance McConnell reconstruyen esta intuición sosteniendo que, si hay un conflicto trágico genuino, esto significa que cada valor o principio en pugna no puede ser derrotado por el otro o por cualquier otro valor o principio que se pretenda hacer intervenir a fin de resolver la contienda.

Entonces, si hay tragedia genuina, esto significa que no puede hablarse de que un valor supere al otro; en otras palabras, como ha indicado Bernard Williams, la sugerencia de que hay valores superables entraña la idea de obligaciones "prima facie"29 que no resulta útil para pensar el desafío de los casos trágicos ${ }^{30}$. Ello así porque, según esta tesitura, en estos conflictos la idea de tragedia reside precisamente en que no hay un valor que supere al otro ${ }^{31}$, de modo que la estrategia de traer la categoría de obligaciones "prima facie" para intentar disolver el problema, puede ser tan tentadora como desafortunada.

Conforme lo anterior, un indicador promisorio de cuándo se produce un conflicto genuino viene dado por la idea de que hay dos requerimientos en pugna que son "inderrotables". Es probable que esta visión esté reforzada por la idea de que cada requerimiento normativo es visto como incondicionado a la Kant y, en consecuencia, se observe que cada uno de ellos está respaldado por "razones absolutas"32, esto, es por razones que no se pueden configurar como prima facie o pro tanto.

Sin embargo, la cuestión está lejos de quedar zanjada. Como señalé anteriormente, hay autores que piensan que hay conflictos trágicos genuinos allí donde está disponible una resolución con sacrificio. Pero una elección con sacrificio podría implicar que, de antemano, se ha logrado inclinar la balanza a favor de uno de los principios en conflicto. Pero esta inclinación

\footnotetext{
${ }^{28}$ Cuando Guastini piensa en conflictos entre principios constitucionales lo hace en términos de "antinomías parciales-parciales". Cfr. Guastini, Riccardo: "Los principios en el derecho positivo", en Distinguiendo, op.cit, p. 170.

${ }^{29}$ Esto explicaría, al menos en parte, porqué Williams piensa que la categoría de los "deberes prima facie" de David Ross es "insuficientemente coflictualista". Véase la respuesta de Williams a Frances Kamm en "Discussion”, in The Legacy of Isaiah Berlin, op. cit., p. 134.

${ }^{30}$ Williams, Bernard: “Conflicto de Valores”, en La Fortuna Moral, Traducción de Susana Marín, Universidad Nacional Autónoma de México, México, 1993, p. 100.

${ }^{31}$ Williams, Bernard: “Conflicto de Valores”, en La Fortuna Moral, op.cit, p. 110; También, en el mismo sentido, Mc Connell, Terrance: "Moral Dilemmas", op. cit., p. 2.

${ }^{32}$ Sobre la categoría "razones absolutas" ver Redondo, Cristina: "Legal Reasons”, Versión Manuscrita, p. 2.
} 
está suponiendo lo que antes denegaba: que el valor elegido se considera que supera, en el caso, al otro valor. Las cosas, así, vuelven a estar en el sitio de origen.

Empero, la cuestión en juego puede ser más profunda. Hay filósofos que sostendrían que hay conflictos trágicos pero en una suerte de nivel "intuitivo". ${ }^{33} \mathrm{Si}$ el agente no es capaz de pasar a un nivel "crítico" que le permita disolver la tragedia, se quedará con la idea, en el mejor de los supuestos, de que la respuesta del caso solo puede estar atada a una elección son sacrificio. Pero, ¿en qué consistiría este nivel “crítico”? Para Richard Hare, que es el autor en el que estoy meditando, este nivel es una amalgama de universalismo kantiano y cálculo utilitarista a la Mill. ${ }^{34}$ En cualquier caso, vale la pena aclarar que este nivel crítico podría tener un contenido distinto si el filósofo que enfoca el problema es una suerte de realista moral como Platón.

En efecto, en el libro I de la República ${ }^{35}$, Céfalo define la idea de 'justicia’ diciendo que ella involucra dos exigencias morales: hablar con la verdad y pagar las deudas. Sócrates refuta rápidamente esta definición con un contra-ejemplo. Sócrates quiere mostrar que no siempre es “correcto” pagar las deudas y que no hacerlo, bajo ciertas condiciones, no implica falla moral. Para mostrarlo Sócrates enfrenta a sus interlocutores con un supuesto dilema en que hay un conflicto entre dos normas morales: una que exige pagar las deudas y otra que exige proteger a otros de un daño. Si la deuda tuviera que ver con un arma (condición uno) y el acreedor estuviese loco y con ella pudiera dañarse a sí mismo o a otro (condición dos), entonces la norma que exige proteger a otros de un daño tiene "prioridad” sobre la norma que exige pagar las deudas, la "supera” en el caso, al menos hasta que la condición (dos) sea removida porque la persona recobró la sanidad mental.

Como puede advertirse, Sócrates cree que hay una respuesta racional al problema que deviene del trato de las normas en términos de derrotabilidad. Pero la derrotabilidad aquí solo es una cobertura lógica de una intuición moral sustantiva, a saber: que hay una suerte de mundo normativo independiente que indica la respuesta correcta para el caso.

\footnotetext{
${ }^{33}$ Hare, Richard: “Cómo resolver los problemas morales racionalmente”, en Racionalidad. Ensayos sobre la racionalidad en ética y política, ciencia y tecnología, op. cit., p. 69. El nivel "intuitivo" es para Hare aquel en que los agentes morales resuelven situaciones "normales" apelando a sus intuiciones ordinarias.

${ }^{34}$ Hare, Richard: “Cómo resolver los problemas morales racionalmente”, en Racionalidad. Ensayos sobre la racionalidad en ética y política, ciencia y tecnología, op. cit., pp. 68-69. Hare cree que, aquellos que ven como enemigos al kantismo y el utilitarismo, han leído deficientemente tanto a Kant como a Mill.

${ }^{35}$ Platón: La República, Libro I, Traducción de José Manuel Pabón y Manuel Fernández Galiano, Atalaya, Madrid, 1993.
} 


\subsection{Las “entidades” en juego}

Otro desacuerdo puede rastrearse, ya no en el terreno de la reconstrucción lógica de los valores en conflicto sino en el terreno del tipo de entidades en conflicto.

Para algunos filósofos, como por ejemplo Bernard Williams, se trata de un conflicto similar al que se verifica entre los deseos ${ }^{36}$. Empero, para otros, se asemejan a los conflictos que se producen entre creencias.

La tesitura de Williams, en la misma vena que la de Berlin, es que en un conflicto entre valores o principios, la elección de uno de ellos no implica que el valor elegido sea verdadero mientras que el otro sea falso. Uno puede haber tomado una elección por uno de los valores y, no obstante ello, sentir remordimiento e, incluso, no ver cómo extraño el hecho de tener que explicar por qué dejó a un lado uno de los valores. ${ }^{37}$

Determinados autores, por ejemplo Andrei Marmor, han visto en posturas como las de Williams, un argumento independiente para defender la corriente anti-teórica en materia moral ${ }^{38}$ desde que los valores no serían tratables en términos lógicos de consistencia ${ }^{39}$. No sé hasta qué punto esto puede ser así, pero en cualquier caso no es un tema que afecte el contenido de la presente investigación.

En realidad, la disputa por el tipo de entidades bajo las cuales reconstruir un conflicto trágico no es baladí. Tras una disputa así hay un debate de fondo sobre la plausibilidad de dos posiciones meta-éticas en pugna: realistas y antirealistas. Entre otras cosas, esto se pone en evidencia por lo siguiente. Para algunos filósofos anti-realistas los casos trágicos serían un test de la falsedad del realismo. ${ }^{40}$ Ello así porque, entre otras cosas, el realismo estaría comprometido con la idea de que hay proposiciones morales que pueden ser verdaderas o falsas en virtud de "hechos morales" independientes de las creencias o convenciones sociales. La idea del anti-realismo, Williams por

\footnotetext{
${ }^{36}$ Williams, Bernard: "Ethical Consistency”, en Problems of the Self, Cambridge University Press, 1993, p. 167.

${ }^{37}$ Williams, Bernard: “Conflicto de valores”, en La Fortuna Moral, op. cit., p. 100.

${ }^{38}$ Ver sobre esto Clarke, Stanley and Simpson, Evan Eds: "Introduction. The Primacy of Moral Practice”, en Anti-Theory in Ethics and Moral Conservatism, State University of New York Press, 1989, pp. 1-25.

${ }^{39}$ Marmor, Andrei: Interpretación y Teoría del Derecho, Traducción de Marcelo Mendoza Hurtado, Gedisa, Barcelona, 2001, p. 89. Desde luego que hay muchas más cosas, no siempre muy claras, en torno al rechazo a la posibilidad de teoría en el terreno moral, por ejemplo, rechazo a una concepción “universalista” de los principios, restricción de la moral a los contextos de prácticas comunitarias contextualizadas temporal y culturalmente, etc.

${ }^{40} \mathrm{Sin}$ duda que es complicado hablar de falsedad de una tesis filosófica e incluso suponer rápidamente que haya algo así como “tesis” en el campo filosófico. Pero no puedo discutir esto aquí que daré por aceptado a los fines de mi argumentación.
} 
ejemplo, es que la reconstrucción es inapropiada porque, precisamente, en un conflicto trágico genuino no operan las categorías verdad-falsedad. El valor o fin sacrificado en la elección no es ni verdadero ni falso.

Otra discusión no zanjada se manifiesta con relación al papel que haya de concederse a la idea de "remordimiento" a la que me referí antes. Para algunos filósofos, claramente para Williams, el remordimiento es un estado mental, un indicador psicológico, de la presencia de un conflicto trágico.

Si hay remordimiento (regret) o culpa hay un indicador de que la acción elegida ha dejado algo correcto en el camino (la noción de pérdida). Esto se vincula con la idea de que la acción no elegida deja intacto un débito o residuo sobre el que habría razones para pensar que también merecería cumplimiento ${ }^{41}$.

La satisfactoriedad de este criterio psicológico es controvertida por aquellos que creen que un conflicto trágico tiene que definirse en el terreno ontológico ${ }^{42}$ y no psicológico ${ }^{43}$. Pero aún si esto fuera cierto, ello tiene consecuencias para las teorías meta-éticas. Por ejemplo, ¿sería compatible admitir que en lo ontológico hay conflictos trágicos genuinos con la existencia de una reconstrucción realista de los valores?

Como dije, para algunos filósofos la existencia de conflictos trágicos es síntoma de la falsedad del realismo moral. Ello así porque el realismo estaría comprometido con la existencia de un mundo en el que no hay violación del principio de contradicción. La idea de incompatibilidad, con todo, es también discutible. Para varios filósofos los casos trágicos, pueden ser compatibles con el realismo moral y, en consecuencia, estos no jaquean al realismo moral (sea lo que fuere que signifique "jaquear" una teoría filosófica). Dados mis propósitos para este trabajo, no necesito ocuparme aquí de estos argumentos ${ }^{44}$.

\footnotetext{
${ }^{41}$ Un particularista "duro" -si es que existe en el mundo algo así- podría ver como insuficientemente particularista la idea de residuo o débito moral. Aquí no puedo explayarme sobre el punto.

${ }^{42}$ En el fondo el problema que se discute podría ser formulado a través de una pregunta como la siguiente: Un conflicto así, ¿es indicador de un déficit de nuestras estructuras conceptuales para conocer el mundo y no un déficit del mundo tal cual es? Si la pregunta tiene algún crédito su tratamiento debe ser diferido para otro trabajo.

${ }^{43}$ Ver McConnell, Terrance: “Moral Dilemmas”, op. cit., p. 9.

${ }^{44}$ Un filósofo que cuestiona la plausibilidad de este tipo de argumentos de los anti-realistas es Shafer Landau, Russ: "Ethical Disagreement, Ethical Objectivism and Moral Indeterminacy”, especialmente pp. 343-344. Desde luego también Foot, Philippa: "Moral Realism and Moral Dilemma”, en Moral Dilemmas, Edited by Christopher Gowans, op. cit., pp. 250-270.
} 


\subsection{Teorías morales y lógica deóntica}

Como puede verse, los criterios que he mencionado hasta ahora están estrechamente conectados y mi distinción preliminar solo es un arma metodológica para ver las cosas más nítidamente. Lo que se discute a partir de estos criterios son dos cosas: por un lado, si hay conflictos trágicos, por el otro, si la respuesta a lo anterior es positiva, cuáles conflictos son genuinamente trágicos.

La discusión sobre ambas cosas es particularmente decisiva para una investigación filosófica, especialmente por la presencia de dos razones: una lógica y la otra de teorías morales.

Con relación a la lógica, concretamente a la lógica deóntica, el problema crucial se resumiría en que, si se admiten conflictos trágicos, se rechazan principios básicos de la lógica deóntica ${ }^{45}$ (especialmente, los principios de “aglomeración” y el "ought imply can” kantiano $\left.{ }^{46}\right)^{47}$. Si se admite la lógica deóntica se rechaza la posibilidad de conflictos trágicos. ${ }^{48}$

Con relación a las teorías morales hay filósofos como Kant, Mill, Ross, ${ }^{49}$ y en el caso del derecho Dworkin, ${ }^{50}$ que piensan que un "adecuado" diseño de una teoría moral podría repeler la existencia de conflictos trágicos genuinos. No puedo aquí discutir qué contaría como un "diseño adecuado" de teorías morales a estos fines, pero baste aquí con observar que, esta manera de pensar explica que, para ciertas teorías morales, o bien los conflictos

\footnotetext{
${ }^{45}$ En contra de esto Valentyne. Ver McConnell, Terrance: "Moral Dilemmas”, op. cit., p. 10.

${ }^{46}$ En la presente reconstrucción tomo nota literal del modo en que discuten los filósofos morales sobre esta cuestión. En esta discusión, el principio kantiano "debe implica puede" es adoptado como un principio de "lógica deóntica". Desde luego que esto no es muy claro porque el "puede" en Kant tiene que ver con una cuestión empírica (lo que podemos hacer desde el punto de vista factual), mientras que el "puede” en un sistema estándar de lógica deóntica tiene que ver con una cuestión normativa (lo que está permitido por una norma).

${ }^{47}$ Por cierto, hay otros principios más. Un comentario detallado de la discusión en Gowans, Christopher: "Introduction. The Debate on Moral Dilemmas”, op. cit., pp. 20-24; También en McConnell, Terrance: "Moral Dilemmas", pp. 3-7.

${ }^{48}$ Ver Conne, Earl: “Against moral dilemmas”, en Moral Dilemmas, Edited by Christopher Gowans, op. cit., pp. 239-249. Por cierto que existe una alternativa "intermedia" entre los extremos de aceptar la existencia de los dilemas morales negando los principios de lógica deóntica o de aceptar la lógica deóntica negando la existencia de dilemas morales. La alternativa consistiría en mostrar la conciliación de ambos extremos. Para un análisis de las distintas estrategias conciliatorias véase McConnell, Terrance: op.cit, p. 10.

${ }^{49}$ Ver McConnell, Terrance: “Moral Dilemmas”, op. cit., p. 2.

${ }^{50}$ Dworkin, Ronald: "Do Liberal Values Conflict?”, in The Legacy of Isaiah Berlin, op. cit. pp. 83-85.; también en "Hart's Postscript and the character of Political Philosophy", op. cit., pp. 1-37.
} 
trágicos no son posibles (alternativa 1) o bien, si son posibles, lo son en un sentido más inofensivo o menos letal (alternativa 2).

Con respecto a la primera alternativa, para una teoría como la kantiana, cuando los deberes morales son perfectos ${ }^{51}$, no hay posibilidad conceptual para la existencia de conflictos trágicos o dilemas morales. Más atrás en la historia de la filosofía, la doctrina socrática de la unidad de las demandas normativas de los dioses (véase el Eutifrón de Platón) implica que la aceptación de conflictos trágicos sería un escándalo inaceptable para el pensamiento ${ }^{52}$ surgido de una descuidada reconstrucción de las fuentes de la normatividad moral (en este caso, las fuentes son divinas). Esta doctrina socrática, como se sabe, es reforzada luego en la tesis de la unidad de las virtudes de Aristóteles y retomada por Tomás de Aquino en la edad media.

Para la segunda alternativa, en cambio, aún si hay conflictos, esto no entraña un peligro irreversible. Ello así porque, tal como piensan los utilitaristas clásicos, siempre hay posibilidad de ordenar en cierto sentido estos conflictos. ${ }^{53}$ Cuáles son los problemas que genera este tipo de "ordenamiento" es algo que no puedo abordar en este trabajo.

Sea como fuere, el punto que estoy tratando de destacar es que el status de los casos trágicos resulta en cierta medida opaco. A esta opacidad se añade el hecho de que los casos trágicos son particularmente complejos pues reenvían a problemas severos para la filosofía. En la tragedia suele observarse gente buena haciendo cosas malas. Aquí hay muchos problemas, pero uno de ellos se vincula con la cuestión metafísica de la libertad. Más allá de la complicada discusión entre los partidarios del determinismo, de un lado, y del anti-determinismo, del otro, el problema con los casos trágicos es que, muchas veces, muestran cosas que les suceden a las personas ${ }^{54}$, no

${ }^{51}$ Un análisis de la cuestión se encuentra en Gowans, Christopher: "Introduction. The Debate on Moral Dilemmas”, op. cit., p. 7. Por cierto, la compilación de Gowans contiene el artículo de Kant "Moral Duties” que es la introducción de Kant a Metaphysic of Morals, pp. 34-51.

${ }^{52}$ E incluso un "escándalo teológico” que surgiría de admitir que, sobre una cuestión determinada, por ejemplo la "santidad”, los dioses expresan ideas contradictorias. En referencia a esto véase el análisis del Eutifrón en Nussbaum, Martha: The Fragility of Goodness. Luck and Ethics in Greek Tragedy and Philosophy, Cambridge University Press, 1986, p. 25.

${ }^{53}$ Ver Gowans, Christopher: “Introduction. The Debate on Moral Dilemmas”, op. cit., pp. 7-9.

${ }^{54}$ Los griegos intuían el problema en el siguiente sentido. Según Martha Nussbaum, ellos pretendían buscar filosóficamente los criterios que permitieran florecer a las personas. Este florecimiento tiene que ver con lo que Nussbaum llama la "auto-suficiencia moral”. Sin embargo, las tragedias muestran, a veces, cómo factores imprevisibles, típicamente la denominada "suerte moral", pone en riesgo esta auto-suficiencia. Ver Nussbaum, Martha: The Fragility of Goodness. Luck and ethics in Greek tragedy and philosophy, op. cit., p. 3 y ss. Según Nussbaum, Kant tendió durante siglos un "manto de sal” sobre el problema pues intentó “elimi- 
cosas que estas hacen $^{55}$, al menos en un sentido obvio o inequívoco de la palabra "hacer".

Así, las tragedias suelen mostrar con frecuencia: i) gente que no es consciente de que está transgrediendo principios morales (Edipo por ejemplo); ii) gente consciente en cierto punto pero dominada por pasiones ingobernables (Otelo por ejemplo). ¿Qué papel jugaría en el caso i) la hipótesis de “responsabilidad moral”? Qué papel, en el caso ii) jugaría la idea de libre elección?

La cuestión es complicada por donde se la mire. Más allá de la respuesta que se le pueda otorgar a i) hay filósofos que discrepan en el enfoque mismo de la cuestión. Para filósofos estilo Nietzche incluso podría ser errado hablar de "transgresión"; para estos filósofos los casos trágicos no serían, en antagonismo con la tesis hegeliana, de naturaleza moral.

En cambio, para otros filósofos pensar en que hay casos trágicos, $\mathrm{y}$ pensar que son cosas que le pasan a la gente y no cosas que éstas hacen, es estar inmerso en una trampa mental. Esta es la forma de pensar de Tomás de Aquino para quien los casos trágicos no existen de forma genuina y su relevancia a lo sumo tiene lugar a la hora de identificar acciones pecaminosas $^{56}$.

Con respecto a ii) hay también mucho para decir. Por ejemplo, para filósofos como Platón o Aristóteles la tragedia, en este sentido ii), no revelaría la impotencia de la razón para gobernar acciones sino un déficit en la educación y disciplinamiento de las pasiones.

narlo" mediante la creación de un reino moral "incondicionado" por los avatares que ocurren en el mundo empírico. Esto explica toda una maquinaria conceptual destinada a eliminar la posibilidad de dilemas morales genuinos Ver Nussbaum, Martha: The Fragility of Goodness. Luck and Ethics in Greek Tragedy and Philosophy, op. cit., p. 4.

${ }^{55}$ En realidad, como ha mostrado Terrance McConnell puede haber dilemas morales "auto impuestos” y dilemas impuestos al agente "por el mundo" (que es lo que sugiere la afirmación del texto). Ver McConnell, Terrance: "Moral Dilemmas”, op. cit., p. 9.

${ }^{56}$ Para el Aquinate los dilemas morales podían ser reconstruidos como frutos de un error producido en la “conscientia”. Debido a una percepción falsa uno podría creerse obligado por deberes incompatibles. Pero la contradicción, nuevamente, es un escándalo lógico surgido de una conciencia que juzga falsamente. La contradicción no es genuina en cuanto se puede ver que hay dos deberes que es menester distinguir: lo que Tomás llamaba deberes per se y lo que llamaba deberes per accidens. Como ambos deberes refieren a niveles distintos no hay conflicto genuino, aunque Tomás admite que alguien pueda sentirse obligado (no estar obligado) por un deber per accidens surgido del error. A diferencia de los trágicos griegos Tomás no imputa estos errores a la fatalidad (correlaciones legaliformes o características del mundo no conocidas por el agente) ni a la divinidad -algo que claramente no puede- sino a la pecaminosidad humana. Un tratamiento detallado de esta posición se puede hallar en MacIntyre, Alasdair: Justicia y Racionalidad. Conceptos y contextos, Traducción y presentación de Alejo José. G. Sison, Ediciones Internacionales Universitarias, Madrid, 2001, pp. 189-190. 
Para otros, la idea misma de un conflicto de valores no resolubles mediante el ejercicio de la razón (sea lo que fuere que esta signifique) no puede más que llevar coherentemente a la idea de una elección radical como la que propugna Kierkegaard con relación a la colisión inevitable entre los valores “estéticos” y los “éticos”. ${ }^{57}$

\section{Tragedia y derecho. Los desafíos}

Como he anticipado en la introducción al trabajo, la tesis central que quiero explorar consiste en sostener que los conflictos trágicos, si son genuinos, ponen al descubierto los límites de la racionalidad del derecho.

"Límites a la racionalidad del derecho" en el siguiente sentido: que, si hay conflictos trágicos genuinos, no habría argumentos jurídicos que apoyaran racionalmente qué hacer en un caso trágico.

Pero si esto se admite, una situación trágica no solo no sería eliminable del derecho sino que tampoco podría aspirarse a dar una respuesta correcta o racional en los casos trágicos.

Un filósofo del estilo de Dworkin podría intentar replicar esta conclusión que, a primera vista, podría resultar chocante. Desde luego que aquí no intento practicar exégesis alguna de Dworkin pero pienso que él podría sostener que los límites de la razón existen en la medida en que el derecho es divorciado de un sustento moral determinado. Si el derecho tiene una conexión conceptual justificatoria con la moral, allí donde el derecho muestre vacilación, la moral puede ayudar a encontrar la respuesta correcta para el caso.

Por cierto que este argumento tiene aspectos a considerar. Yo no puedo, sin embargo, considerarlos aquí. Sólo diría que el problema de determinación de respuesta que el derecho debiera enfrentar en un conflicto trágico es el mismo problema que podría enfrentar cualquier sistema moral. No estoy muy seguro de qué tipo de moral defiende Dworkin. Sigo viendo difuso si es una moral positiva o ideal y, aunque fuese ideal ${ }^{58}$, veo un tanto extraño que ella coincida tanto con ciertos valores liberales de la cultura norteamericana. Pero, en todo caso, escapa a este trabajo discutir estas cuestiones.

En lo que sigue quisiera dejar delineados a grandes rasgos algunos de los principales desafíos que los juristas, especialmente los jueces, tendrían

\footnotetext{
${ }^{57}$ Aunque Kierkegaard pareciera favorecer tácitamente la preeminencia de los valores éticos (por ejemplo la "fidelidad matrimonial” por sobre los estéticos. Ver tratamiento de la cuestión en MacIntyre, Alasdair: Tras la virtud., Traducción castellana de Amelia Valcárcel, Crítica, Barcelona, 2001, pp. 60-65.

${ }^{58}$ Por cierto, aquí no discutiré el status de la categoría “moral ideal”.
} 
que enfrentar si admitieran que hay conflictos trágicos genuinos ${ }^{59}$. Vale la pena remarcar que lo que presentaré será una suerte de mapa conceptual muy general; en consecuencia, la discusión detallada de cada desafío, discusión que requiere del ofrecimiento de más distinciones de las que aquí presento, se difiere para futuros trabajos ${ }^{60}$.

\subsection{El desafío "institucional” del derecho}

Isaiah Berlin y Bernard Williams han propagado la idea de que la resolución de conflictos trágicos no es tanto una demanda lógica, vgr., disolver inconsistencias, como social o institucional ${ }^{61}$. En buena medida esta forma de encarar el asunto tiene que ver con el tipo de reconstrucción conceptual que los autores creen que mejor muestra la naturaleza de un conflicto trágico.

Pero, ¿en qué consistiría esta demanda institucional? Creo que la respuesta a esta pregunta se tiene que apoyar, en el caso del derecho, en la existencia, en la mayoría de los ordenamientos jurídicos del mundo, de un deber inexcusable de juzgar puesto en cabeza de los jueces. Tras este deber

${ }^{59}$ No es mi cometido para este trabajo presentar una "taxonomía” de tipos posibles de conflictos trágicos en el derecho. Simplemente aquí tomo la categoría "conflicto trágico” como instrumento para apreciar ciertos límites en la racionalidad jurídica y moral. Desde luego, la cuestión es sumamente complicada principalmente por dos razones. La primera y más obvia tiene que ver con la fuerte controversia en orden a caracterizar qué tipo de “conexión” y qué tipo de "moral” podría estar en juego cuando se habla de conexiones entre moral y derecho. La segunda es que uno podría empezar distinguiendo entre conflictos trágicos en la moral surgidos de la colisión entre requerimientos morales (conflictos trágicos morales) de los conflictos trágicos en el derecho surgidos de colisiones entre requerimientos jurídicos, típicamente los enderezados a un juez (conflictos trágicos jurídicos). Sin embargo, podrían existir conflictos trágicos que devengan de la colisión, por ejemplo en la conciencia de un juez, de valores jurídicos con valores extra-jurídicos o lisa y llanamente valores morales. Para entender esto último, y solo a título de ejemplo, piénsese en un caso como el del “insumiso penal” en el código penal español -insumisión motivada en una “objeción de conciencia”- donde según algunos filósofos el juez "o aplica la ley o hace justicia”. Cfr. Atienza Manuel: "Los límites de la interpretación constitucional”. De nuevo sobre los casos trágicos, en Interpretación jurídica y decisión judicial, op. cit., p. 202. Por cierto que el caso del insumiso podría reconstruirse de manera distinta a como lo hace Atienza, por ejemplo, alegando que, estrictamente, el conflicto trágico aquí es entre "valores jurídicos” (conflicto trágico jurídico) y no entre un valor jurídico (aplicar la ley) y un valor moral (hacer justicia). También podría negarse que el caso ejemplifique un auténtico dilema moral desde el momento en que se muestra que la superación de un valor por otro tiene algún tipo de control racional como sostiene Atienza. Pero, en todo caso, aquí no puedo entrar a discutir estos aspectos.

${ }^{60}$ Insisto en que el propósito de este trabajo es ofrecer un mapa general; por ende, las distinciones posibles entre diferentes tipos de conflictos normativos y una caracterización de distintos niveles de conflictos trágicos posibles según los distintos tipos de problemas (por ejemplo según distintos tipos de inconmensurabilidad) es una tarea que se proyecta para un trabajo independiente.

${ }^{61}$ Ver Williams, Bernard: “Conflicto de Valores”, en La Fortuna Moral, op. cit., pp. 101, 108-109. 
podría encontrarse la existencia de una demanda de prestación efectiva de justicia.

Aunque no lo es, debería ser claro, empero, que la existencia de esta demanda no precluye la existencia de conflictos trágicos per se. Serían necesarios argumentos de alguna teoría de la argumentación racional, así como de teoría moral y lógica deóntica, que mostrasen porqué los conflictos trágicos son meramente aparentes porque, de la existencia de un deber de resolver casos, no se elimina per se la idea de que haya conflictos que no se puedan resolver en forma "racional" o "correcta", sea lo que fuere que estas expresiones signifiquen.

La tesis que postule la existencia de conflictos que no se puedan resolver en forma racional o correcta colisiona, de algún modo, con un trasfondo compartido en buena medida por muchos juristas y filósofos.

Según este trasfondo, es un lugar común suponer que una característica de ámbitos normativos como el derecho o la moral estriba en su función de guiar comportamientos. Para que esta función sea satisfecha, el derecho o la moral deben tener capacidad de determinar qué debe hacerse en situaciones particulares o clase de situaciones.

Sin embargo, como intentaré mostrar más adelante en este trabajo, la existencia de conflictos trágicos pone en discusión esta capacidad de determinar soluciones. Sin intención de presentar ahora un panorama exhaustivo, uno podría pensar que la práctica constitucional suministra ejemplos de conflictos entre valores que intentan maximizar ciertos principios constitucionales y que éstos conflictos, si tienen carácter trágico, son difícilmente tratables.

Generalmente, los principios constitucionales asignan derechos. El conflicto entre valores subyacentes a principios, entonces, afecta el ámbito de los derechos que una Constitución procura garantizar. La relevancia teórica y práctica de esta cuestión es compleja porque, por ejemplo, de un conflicto entre principios constitucionales no sólo se siguen consecuencias para el análisis de la protección de derechos, sino que también hay consecuencias para la justificación del diseño institucional de una comunidad. ${ }^{62}$

Como se sabe, el núcleo de la mayoría de las denominadas tesis libertarias está dado por una afirmación del pluralismo de valores. Aunque existe controversia en torno a la idea de si el pluralismo de valores lleva necesaria-

\footnotetext{
${ }^{62}$ No pretendo defender aquí ninguna aproximación específica a la llamada "naturaleza institucional del derecho".
} 
mente a fenómenos como el particularismo moral ${ }^{63}$, el relativismo moral ${ }^{64} \mathrm{O}$ la inconmensurabilidad de valores ${ }^{65}$, hay bastante acuerdo en que la existencia de valores plurales lleva inevitablemente a conflictos normativos. ${ }^{66}$

Ante esto, se presenta un problema que no escapa a la discusión contemporánea. ¿Qué tipo de diseño institucional exigiría el liberalismo comprometido con la tesis del pluralismo de valores? ¿Qué tipo de diseño sería necesario construir a efectos de resolver racionalmente conflictos entre valores? ¿Hay alguna manera de hacer compatibles dentro del liberalismo el presupuesto de la pluralidad de valores con los presupuestos de organizar un Estado de Derecho en el cual las decisiones de las autoridades tengan cierta estabilidad y sean previsibles? Con otras palabras, ¿hay alguna relación necesaria entre el liberalismo y un diseño institucional específico?

Por desgracia no puedo en el contexto de este trabajo responder todas estas preguntas. Sin embargo, desearía realizar las siguientes observaciones.

\footnotetext{
${ }^{63}$ Por ejemplo Hans Joas piensa que el pluralismo de valores de Berlin es conciliable con el universalismo moral, aunque admite que son necesarios argumentos explícitos para mostrar adecuadamente esto. Ver Joas, Hans: "Pluralismo de Valores y Universalismo Moral”, Traducción de Luis Felipe Segura, en Creatividad, acción y valores. Hacia una teoría sociológica de la contingencia, Biblioteca Signos, México, 2002, p. 50.

${ }^{64}$ La respuesta de Berlin a esto es negativa. Lo contrario supondría adherir a la idea de que los valores son subjetivos, posición que Berlin descarta. Berlin, Isaiah: El Fuste Torcido de la Humanidad, op. cit., pp. 30-36. Ratificando esta posición véase la introducción que Bernard Williams realiza a Conceptos y Categorías. Ensayos Filosóficos, de Isaiah Berlin, Traducción de Francisco González Aramburu, Fondo de Cultura Económica, México, 2004, p. 25; también considerar a Charles Taylor, quien, en "Plurality of goods", in The Legacy of Isaiah Berlin, op. cit., p. 113, mantiene que la tesis sobre los valores de Berlin presupone algo así como una clase de "realismo moral" o "cognitivismo". Sin embargo esta lista de apoyos a Berlin no torna en indisputable la posibilidad de considerarlo relativista en algún sentido. En primer lugar porque no creo que el argumento del "realismo moral" o el "objetivismo" sea condición "suficiente" para descartar tesis relativistas morales o conceptuales en la posición de Berlin. De hecho, hay filósofos a la Dancy que se asumen como realistas morales y particularistas duros al mismo tiempo. Pero además repárese en lo siguiente. Una de los apoyos de Berlin para su pluralismo de valores se basa en Herder que postulaba una tesis sobre inconmensurabilidad de culturas. Uno podría pensar, al menos a modo de hipótesis, que la tesis de Herder da pie para la inconmensurabilidad en un sentido que guarda cierto "parecido de familia" con la tesis según la cual la comparabilidad entre culturas es problemática en cuanto la misma supone algún tipo de evaluación y ésta es relativa a una cultura. En todo caso habría que pensar si no hay algún sentido en que Berlin sea un particularista.

${ }^{65}$ Ruth Chang controvierte esto de la misma manera en que el monismo no lleva necesariamente a la comparabilidad. Chang, Ruth: "Introduction”, en Incommensurability, Incomparability and Practical Reason, Edited by Ruth Chang, Harvard University Press, 1997, p. 16.

${ }^{66}$ En sintonía con esta idea de Isaiah Berlin se encuentra Atienza, Manuel: "Los límites de la interpretación constitucional”. De nuevo sobre los casos trágicos, op. cit., p. 211.
} 
Lo primero que hay que observar aquí es que no es posible responder estas preguntas hasta que no se identifique el tipo de liberalismo en juego ${ }^{67}$. Pero aún identificado el tipo de liberalismo la respuesta puede ser vacilante por lo que digo a continuación.

Concretamente, los juristas procuran responder este tipo de preguntas a través de dos instrumentos: el atrincheramiento o la protección de derechos bajo un coto vedado y la institución de los jueces como órganos de control de la constitucionalidad de las leyes que refieren a derechos.

Sin embargo, tampoco aquí se verifica acuerdo con respecto a la naturaleza de estos dos instrumentos. Precisamente, buena parte de este desacuerdo, que tiene su origen en las discrepancias filosófico políticas sobre el diseño institucional al que debería comprometer el liberalismo, se enraíza en las distintas interpretaciones que los juristas le adjudican a la asunción de que las sociedades liberales tienen como característica la existencia de valores diversos, conflictivos y cambiantes.

Para algunos, como Garzón Valdés ${ }^{68}$ por ejemplo, estas características son las que avalan la necesidad, por un lado, de contar con un coto de principios constitucionales que esté vedado a la agenda de discusión legislativa ordinaria y, en consecuencia, que no pueda ser afectado por la mayoría, por otro lado, de contar con órganos como los judiciales que estén legitimados para controlar la constitucionalidad de las leyes votadas por la mayoría.

Para otros, como por ejemplo Jeremy Waldron ${ }^{69}$, tesis del estilo de las que sustenta Garzón Valdés son disputables porque es sumamente discutible que sea posible aislar un coto vedado de principios y que los órganos judiciales estén legitimados sin más a controlar la constitucionalidad de las leyes. Respecto de lo primero Waldron suministra diversos argumentos que pretenden minar la presuposición del carácter determinado de los principios que conformarían ese coto; respecto de lo segundo, uno de los argumentos es que los jueces no pueden estar legitimados para controlar la constitucionalidad de las leyes debido a que por lo general no son elegidos democráticamente.

\footnotetext{
${ }^{67}$ Por ejemplo, Roberto Gargarella defiende un liberalismo igualitario en cuanto al diseño institucional del funcionamiento de las mayorías y control judicial de constitucionalidad con todo lo que esto implicaría. Ver Gargarella, Roberto: "El contenido igualitario del constitucionalismo”, en La Relevancia del Derecho. Ensayos de filosofía jurídica, moral y política, Pablo Navarro y María Cristina Redondo Compiladores, Gedisa, Barcelona, 2002, especialmente p. 217 y ss.

${ }^{68}$ Garzón Valdés, Ernesto:”Representación y Democracia”, en E. Garzón, Derecho, Ética y Política, Centro de Estudios Constitucionales, Madrid, 1989, especialmente pp. 644-645.

${ }^{69}$ Por ejemplo, Waldron, Jeremy: “A Right-Based Critique of Constitutional Rights, en Oxford Journal of Legal Studies, N.13, 1993, pp. 18-51.
} 
¿Cómo encaja toda esta discusión sobre diseño institucional con la posibilidad de que existan casos trágicos genuinos? En forma preliminar a una respuesta concreta a esta pregunta repárese en que, si hay casos trágicos genuinos antes de disputar sobre cuál diseño institucional es viable, hay que dar respuesta al desafío que los casos trágicos generan en la racionalidad misma del derecho. Los diseños institucionales frente a estos casos serían algo así como pilares de piedra sobre el fango, a menos que se ofrecieran argumentos para mostrar lo contrario.

Ahora bien, creo que en la discusión sobre el diseño institucional que mantienen posiciones como las representadas por autores como Garzón Valdés o Waldron la cuestión de posibles conflictos trágicos genuinos tiene suma relevancia. Por ejemplo, el argumento de que hay conflictos trágicos genuinos podría avalar una tesis, estilo Waldron, acerca de la "indeterminación del coto vedado", sosteniendo, por ejemplo, que nada indica que los principios o valores que están en ese coto no sean inconmensurables o no puedan presentar conflictos que lleven a elecciones trágicas, es decir, con sacrificio de algo valioso. Adicionalmente la idea de que en conflictos trágicos genuinos las respuestas de los jueces tendrán serios aprietos para contar como "racionales" podría ser un argumento a sumar en la objeción a la legitimidad de un control de constitucionalidad en cabeza de los jueces.

Pero debería ser claro que esta discusión también es parasitaria de cómo se considere el problema del carácter determinado del derecho y, en concreto, del llamado coto vedado. Un autor como Garzón Valdés adopta como punto de partida la idea de que tal coto es determinado y por ello afirma que se encontraría justificada una imposición de "carga de la prueba" para aquellos que sostengan la indeterminación del coto vedado, basado en el argumento de "elección trágica", para un caso concreto, Para Garzón, mostrar que en un caso se verifica un supuesto de "elección trágica”, del estilo promovido por Isaiah Berlin, es algo que corre por cuenta de quien lo alega ${ }^{70}$.

\subsection{El desafío al carácter "determinado" del derecho}

Un segundo desafío se vincula con el conocido problema del carácter determinado del derecho ${ }^{71}$. Habitualmente se supone que el derecho se encuentra indeterminado cuando: a) hay dudas sobre si una norma es apli-

\footnotetext{
${ }^{70}$ Cfr. Garzón Valdés, Ernesto: “Representación y Democracia”, op. cit., p. 650.

${ }^{71}$ Cristina Redondo examina, por un parte, los diversos sentidos en que puede predicarse que el derecho es un conjunto indeterminado, por otra parte, cuáles son los argumentos de aquellos que oponen el carácter determinado del derecho a cada uno de los sentidos defendidos en el marco de tesis indeterministas sobre el derecho. Sobre todo, es pertinente el análisis que Cristina Redondo desarrolla de la existencia de "respuestas múltiples” para un caso en oposición a la tesis de respuesta única. Ver Redondo, Cristina: “Teoría del Derecho e Indeterminación
} 
cable a un caso (vaguedad); b) no hay respuesta para un caso (lagunas normativas); c) hay respuestas pero se consideran axiológicamente deficientes (lagunas axiológicas); d) hay una pluralidad de respuestas conflictivas.

El problema de la indeterminación, como se sabe, no es patrimonio exclusivo del derecho ${ }^{72}$. Pero si hay alguna "peculiaridad" para el derecho ésta estriba en que no hay acuerdo con respecto a la aceptación y a cómo concebir el alcance de la vaguedad en el derecho (piénsese en Dworkin) y cómo concebir y si realmente hay cosas como las lagunas normativas (por ejemplo Raz tiene un argumento para negarlas) y cómo se podrían -si pueden- diferenciarse de otras lagunas como las axiológicas ${ }^{73}$.

Lo interesante aquí es que la hipótesis d) referida a pluralidad conflictiva de valores tiene relación directa con el problema del carácter determinado del derecho. Recuérdese que un test de la existencia de tragedia en un conflicto suele apoyarse en la idea de que los valores o principios en conflicto son inconmensurables.

A este respecto, Joseph Raz piensa que una de las fuentes de indeterminación del derecho, las "lagunas jurídicas", tienen que ver, precisamente, con la existencia de normas o principios inconmensurables ${ }^{74}$ (según Raz esto es así cuando "el derecho habla con muchas voces". ${ }^{75}$

Cuando esto ocurre, el efecto de la inconmensurabilidad, podría pensarse, es similar al efecto de la vaguedad de predicados: queda afectada seriamente la aplicación del principio de bivalencia al derecho.

Si lo anterior fuese así, las proposiciones normativas con las que los juristas describen el derecho no serían ni verdaderas ni falsas; por consiguiente, de manera análoga ${ }^{76}$ a los efectos que produce la vaguedad de

Normativa”, en Conocimiento Jurídico y Determinación Normativa, José Juan Moreso, Pablo Navarro y Cristina Redondo Editores, Fontamara, 84, Méxíco, 2002, pp. 104-105.

${ }^{72}$ En rigor, se podría decir que el problema de la indeterminación del derecho forma parte de una familia de problemas relevantes por sus consecuencias para el análisis de la naturaleza del derecho, las relaciones de éste con la moral, el carácter vinculante de la autoridad del derecho, etc. Dado que este trabajo tiene carácter introductorio a la problemática general de los conflictos trágicos no puedo aquí ocuparme con detalle de estos problemas.

${ }^{73}$ Ver Rodríguez, Jorge: "La imagen actual de las lagunas en el derecho”, Versión manuscrita.

${ }^{74}$ Joseph Raz examina situaciones en que los requerimientos normativos en pugna son inconmensurables, motivo por el cual ninguno de los requerimientos derrota al otro y, en consecuencia, el conflicto no se puede resolver racionalmente. Ver Raz, Joseph: "Legal Reasons, Sources, and Gaps", en The Authority of Law. Essays on Law and Morality, Clarendon Press Oxford, Oxford, 2002, p. 75.

${ }^{75}$ Raz, Joseph: "Legal Reasons, Sources, and Gaps”, en The Authority of Law. Essays on Law and Morality, op. cit, p. 77.

${ }^{76}$ No todos aceptarían esta analogía que asemeja los problemas de indeterminación basados en la vaguedad de predicados con los problemas que surgen de la inconmensurabilidad de valores. 
ciertos predicados, la inconmensurabilidad sería un foco importante de indeterminación del derecho y, por tanto, su presencia podría añadirse a esta discusión.

\subsection{El desafío a la "conmensurabilidad” de valores o principios jurídicos}

Aquí, como es posible ver, el desafío al carácter determinado del derecho que plantearían los casos trágicos lleva directamente a un tercer desafío: el de la inconmensurabilidad entre valores. Típicamente, para el caso del derecho, a la inconmensurabilidad de los valores constitucionales que ciertos principios jurídicos de rango constitucional procuran maximizar.

El desafío es que, si las alternativas son incomparables, entonces, la elección justificada está imposibilitada y el rol de las razones jurídicas ${ }^{77}$, de guiar la elección está seriamente restringido ${ }^{78}$; de aquí devendría, en parte, la tesis de los límites de la racionalidad jurídica que uno podría plantear en el estilo de Jon Elster.

El problema dramático de la inconmensurabilidad es que, si es cierto que ésta existe, no sería posible activar el método de ponderación a efectos de resolver el conflicto, determinando, en un esquema de "ordenamiento" qué principio es "mejor" que el otro, y en consecuencia, tiene "prioridad" sobre el otro.

Sin embargo, aquí, cuando menos, se presentan tres cuestiones para investigar que han sido sugeridas con mucho detalle por parte de Ruth Chang y que yo no podré tratar en este trabajo.

La primera cuestión es que es menester distinguir "inconmensurabilidad" de "incomparabilidad"79. La inconmensurabilidad apela a la idea de que no hay una escala cardinal para medir valores, pero no dice nada respecto de la posibilidad de compararlos en mérito de ciertas propiedades de las cosas que se pretenden comparar. Ésta es la idea de filósofos del derecho como Alexy que preconizan que la ponderación "racional" se apoya en un ordenamiento "débil" de tipo ordinal. ${ }^{80}$ En consecuencia, cuando se dice

\footnotetext{
${ }^{77}$ Pese a lo extendido que se encuentra el lenguaje de las “razones", no es muy claro qué se quiere significar con el mismo. Por 'razones jurídicas' aquí simplemente entiendo la existencia de normas jurídicas de algún tipo, por ejemplo principios constitucionales, que suministran argumentos para justificar acciones u omisiones de algún tipo.

${ }^{78}$ Es lo mismo que Ruth Chang afirma con relación a la llamada "razón práctica". Ver Chang, Ruth: "Introduction", en Incommensurability, Incomparability and Practical Reason, op. cit., p. 3.

${ }^{79}$ Chang, Ruth: "Introduction”, en Incommensurability, Incomparability and Practical Reason, op. cit., pp. 1-2.

${ }^{80}$ Alexy, Robert: “On Balancing and Subsumption. A Structural Comparison”, en Ratio Juris, Vol.16, Nº.4, 2003, p. 440 y ss. También puede verse "Sistema Jurídico, Principios Jurí-
} 
que, en cierto caso, "vale más” el principio de la libertad de expresión que el principio del derecho al honor, no se hace equivalente este "vale más" a «"vale 1.5 más” o "vale 3.4 más", etc.». Precisamente esto muestra por qué la idea de "peso" que se adjudica (independientemente de cuál fuese la naturaleza de esta adjudicación) a principios o valores en conflicto no puede ser tomada "al pie de la letra".

La segunda cuestión es que, aquellos que alegan rápidamente inconmensurabilidad, suelen obviar la existencia de algún "valor cobertura" ${ }^{11}$ que permita desarrollar argumentos comparatistas. Así, uno podría decir, como Isaiah Berlin, que no hay forma de comparar las tragedias de Sófocles con las de Racine ${ }^{82}$. Sin embargo, si uno puede encontrar un valor cobertura subyacente, por ejemplo el "talento literario para escribir tragedias", la posibilidad de comparación aun no habría sido eliminada.

La tercera cuestión, que aquí solo presentaré de manera muy general, es que, según Ruth Chang, muchas tesis que se presentan en apoyo de la incomparabilidad de valores, por ejemplo la tesis del pluralismo de valores, si son reconstruidas profundamente, muestran que no son argumentos en verdad compulsivos. Ruth Chang ensaya diversos argumentos para mostrar porqué son las tesis "comparativistas" las que tienen chance de ganar la batalla. En esta línea, un argumento nodal de Chang es que hay que distinguir entre "fallas formales" y "sustantivas" de comparación.

Para Ruth Chang si hay una falla formal ello significa que las alternativas no son comparables, pero esto no es lo mismo que decir que son incomparables ${ }^{83}$.

$\mathrm{Si}$, como sugiere Ruth Chang, la distinción entre fallas formales y sustantivas de la comparación traza la esfera de acción de la razón práctica, entonces la razón práctica nunca enfrenta a los agentes con alternativas de

dicos y Razón Práctica”, en Derecho y Razón Práctica, Traducción de Ernesto Garzón Valdés, Fontamara, México, 2002, p. 17.

${ }^{81}$ Por 'valor cobertura' se entiende cualquier consideración que permita realizar una comparación en términos evaluativos. Ver Chang, Ruth: "Introduction”, en Incommensurability, Incomparability and Practical Reason, op. cit., p. 5.

${ }^{82}$ Berlin, Isaiah: El Fuste Torcido de la Humanidad, op. cit., p. 28.

${ }^{83}$ La condición formal de una comparación es que haya un valor de cobertura con respecto al cual la comparación pueda proceder. Esto podría no ocurrir si: i) el valor de cobertura no existe o ii) aún si está establecido o implicado no cubra los items. Sin referencia a un valor con respecto al cual la comparación proceda, la no comparación puede ser entendida. Una falla sustantiva de comparabilidad, por el contrario, presupone que las condiciones de posibilidad de la comparabilidad y la incomparabilidad se mantienen, pero como cuestión sustantiva, los items no pueden ser comparados con respecto al valor cobertura. Ver Chang, Ruth: “Introduction”, en Incommensurability, Incomparability and Practical Reason, op. cit., pp. 27-34. 
elección entre ítems respecto de los cuales no se puede establecer una comparación debido a que hay una falla formal de comparación.

Con arreglo a este tipo de distinciones, es preciso volver sobre aquellos filósofos del derecho, como Riccardo Guastini por ejemplo, que son escépticos en materia de ponderación y que, en este sentido, sostienen que el producto de la ponderación es el resultado de lo que le parece a un juez. ${ }^{84}$ Lo que le parece a un juez es parte de un juicio subjetivo que repele la posibilidad de comparación. Pero, si Chang tiene razón, autores como Guastini no pueden sostener una visión así de la ponderación a menos que muestren que ésta no es posible debido a una real falla formal para comparar principios o valores en conflicto o debido a algún otro argumento a favor de la incomparabilidad.

\subsection{El desafío a la posibilidad de ponderación de principios o valores jurídicos en conflicto}

Un cuarto desafío se vincula con dos cuestiones conectadas: por una parte, cuál es la naturaleza del conflicto entre valores o principios jurídicos, por caso los “constitucionales”, por la otra, cómo concebir el método de la ponderación o balance.

Pese a lo obvio que pueda parecer la mención de estas dos cuestiones no creo ser cándido si afirmo que ellas no terminan de ser totalmente transparentes para los filósofos del derecho. No puedo ni por asomo defender in extenso mi afirmación. Pero, en cambio, permítaseme señalar que, si un caso es genuinamente trágico, pareciera que ni siquiera puede aspirarse a la ponderación como método específico de ordenamiento de conflictos entre principios. Esto por dos motivos: o bien porque se considera que los valores o principios en conflicto son inderrotables o bien porque se consideran inconmensurables. En el primer caso, la ponderación estaría bloqueada desde el momento que la ponderación supone la posibilidad de mostrar que uno de los valores o principios tiene mayor peso en el caso y, en consecuencia, “derrota” al otro. En el segundo caso porque la ponderación supone, ante todo, la posibilidad de comparar los principios en conflicto, estableciendo cuál de ellos “es mejor” o "peor” o "vale tanto” como el otro.

En realidad, la ponderación y cualquier otra noción que intente racionalizar un conflicto, podría colapsar si se aceptase que hay conflictos trágicos genuinos. Esto podría sonar a una verdad banal, sin embargo, filósofos del derecho importantes y que se han ocupado de estas cuestiones, no han sido muy consistentes al respecto. Ello así porque han admitido, por una parte, que hay

\footnotetext{
${ }^{84}$ Guastini, Riccardo: “Los principios en el derecho positivo”, en Distinguiendo, op. cit., p. 170.
} 
casos trágicos en sentido estricto, y por la otra, han sugerido la posibilidad de dar argumentos que, aun si más costosos de obtener, no escapen por completo $a$ un control racional, sea lo que fuere que esto signifique. Un filósofo del derecho como Manuel Atienza sería un ejemplo de mi afirmación. ${ }^{85}$

Con todo, un test que suele emplearse para mostrar que se está ante la presencia de un caso trágico en sentido estricto es, como indiqué antes, el de la incomparabilidad o inconmensurabilidad de los valores, o principios constitucionales para el caso del derecho. La tesis de que hay valores en conflicto que son incomparables tiene un efecto concreto: impide comparar y ordenar un eventual conflicto normativo. No es posible, en consecuencia, sostener que el principio P1 es "mejor" que el principio P2, o es "peor", o "vale tanto como...".

Ahora bien, frente al escepticismo respecto de la posibilidad de resolver conflictos trágicos y que esta resolución tenga carácter racional, los juristas insisten en su confianza de que la ponderación es un instrumento que permite resolverlos de manera racional. Sin embargo, no tienen acuerdo entre ellos respecto de qué implica la resolución de estos conflictos y cuál es la naturaleza de la ponderación.

Respecto de las dos cuestiones mencionadas, los juristas parecen adoptar dos actitudes cuyo análisis detallado pospongo para un trabajo independiente, tomando en cuenta las categorías de casos trágicos, inconmensurabilidad e incomparabilidad: i) según la primera es posible por medio de una ponderación establecer un orden jerárquico entre los principios, una relación de precedencia entre ellos que no se agote para un caso concreto sino que pueda extenderse a otros. Ésta, resumidamente, es la posición de filósofos del derecho como Robert Alexy que suscribirían una posición que en filosofía moral se conoce como "universalista" ii) según la segunda es posible emplear la ponderación y resolver el conflicto, pero esta estrategia no elimina la pérdida o el sacrificio del principio dejado a un lado y la resolución vale, "en principio”, sólo para ese caso; en otras palabras, la jerarquía establecida entre esos principios en ese caso no se puede "generalizar" y por ello las jerarquías establecidas entre principios conflictivos son "móviles”. Ésta, resumidamente, es la posición de filósofos del derecho como Riccardo Guastini que defendería una posición que en filosofía moral ${ }^{86}$ se conoce como "particularista".

\footnotetext{
${ }^{85}$ Ver Atienza, Manuel: "Los límites de la interpretación constitucional”. De nuevo sobre los casos trágicos, en Interpretación jurídica y decisión judicial, op. cit., p. 209.

${ }^{86}$ Moreso, José.J: “Guastini sobre la ponderación”, en Isonomía, Revista de Teoría y Filosofía del Derecho, 17, México, 2002. Para una comparación de Alexy y Guastini ver Moreso, José. “Conflicto entre principios constitucionales”, MS.
} 
Desde luego que la cuestión de calificar a un filósofo como particularista o universalista no es baladí. Pero puede transformarse en una cuestión de palabras si no se aclara qué tipo de tesis justificarían uno u otro rótulo. En el presente trabajo no puedo ocuparme de este problema; su tratamiento, con relación a los conflictos trágicos, será examinado en un trabajo independiente.

Adicionalmente a las posiciones que he comentado arriba, hay filósofos del derecho, como José Moreso por ejemplo, que sostiene una posición si se quiere intermedia, que es la siguiente. Si bien se puede admitir que el conflicto entre principios pone en cuestión la racionalidad subsuntiva y que la ponderación desarrolla típicamente una racionalidad narrativa, el objetivo de la ponderación debe ser la construcción de reglas que puedan generalizarse para otros casos y prioricen, por tanto, una racionalidad subsuntiva.

En cualquier caso, las observaciones que he realizado, podría decirse, son de público conocimiento de los filósofos. Sin embargo, mi idea es que el problema de la ponderación de principios constitucionales ha obviado los desafíos que los conflictos trágicos podrían suscitar. Esto para no hablar del desafío que todavía los filósofos prácticos tienen ante sí de lograr acuerdos firmes en torno al alcance de tesis particularistas y universalistas en el campo moral y jurídico y desmenuzar una a una todas las consecuencias de las categorías racionalidad subsuntiva y narrativa, exponiendo sus posibles relaciones ${ }^{87}$.

\section{La tesis de los límites de la racionalidad jurídica, su alcance y consecuencias}

En este trabajo me he ocupado de los llamados conflictos trágicos o dilemas morales.

He mostrado que, pese a que no hay acuerdos conceptuales claros respecto de cuándo un conflicto trágico es genuino, los filósofos en general suelen aceptar que, si hay cosas así, ello significa que la "racionalidad práctica”, sea en versión “instrumental”, sea en versión “deontológica”, sea en el terreno jurídico o en el moral, se encuentra limitada.

Debería ser patente que, cuando hablo de cosas tales como "racionalidad jurídica” y "límites” no estoy dando por sentado que estas expresiones sean claras y haya acuerdo sobre ellas. En rigor, no he pretendido defender ninguna tesis fuerte sobre el contenido específico de estas expresiones ni brindar un alegato a favor de un escepticismo radical estilo Kripke o Pirro acerca

\footnotetext{
${ }^{87}$ Por ejemplo, en esta línea de trabajo puede consultarse Bouvier, Hernán: "Particularismo y Generalismo. Un análisis de las tensiones entre racionalidad narrativa y subsuntiva en el ámbito teórico y jurídico”, en Analisi e Diritto, a cura di P. Comanducci y R. Guastini, Génova, 2004.
} 
de la posibilidad de que no haya respuestas correctas o racionales para la mayoría de los casos. Stricto sensu, la tesis ha sido ceñida a los conflictos trágicos genuinos y, por ende, no he pretendido decir que la creencia en que pueda haber a veces respuestas racionales o correctas sea pura ilusión.

Mi propósito, más bien, ha sido modesto desde que no ha pretendido despejar ${ }^{88}$ cuestiones sobre las que grandes mentes, Platón, Aristóteles, Tomás de Aquino, Kant, Hegel, etc., han hecho tanto por aclarar.

Más bien la idea de "límites" que he tenido en mente ha estado conectada con ciertos "desafíos" que, me parece, se le pueden plantear al derecho una vez que se asuma que hay al menos algunos $\operatorname{casos}^{89}$ que entrañarían alguna versión de conflicto trágico genuino.

Ahora bien, ¿es la tesis sobre los límites de la racionalidad jurídica irrecusable?

La respuesta creo que debe ser negativa. La cuestión de los "límites" puede ser variable y no fija en la medida en que haya filósofos que desarrollen argumentos profundos para correr esos límites lo más que se pueda, habilitando a que ámbitos como la moral o el derecho puedan aspirar a brindar respuestas a conflictos trágicos, en cuyo caso éstos se revelarían como aparentes.

En el caso del derecho, hay filósofos como Ronald Dworkin que impugnarían la tesis de los límites y ello no le convertiría per se en un irracional como en el que estaría pensando Jon Elster.

Desdichadamente, aquí no puedo tratar con detalle el conjunto de posiciones que una teoría compleja como la de Dworkin proporciona en orden a repeler la idea de conflictos trágicos genuinos. Aunque esta tarea es desarrollada en un trabajo independiente ${ }^{90}$, téngase en cuenta que Dworkin acepta que en casos difíciles, aun si no se puede demostrar, hay respuestas

\footnotetext{
${ }^{88}$ Filósofos no analíticos o que entienden el análisis en una vena metafísica dirían "resolver". Cuando digo "despejar" no lo hago tanto para sugerir qué tipo de compromiso metodológico adquiero sino para ser un tanto más moderado o prudente en cuanto a mis posibilidades para "liquidar" -si esto cupiera- problemas tan agudos como los que he tratado. De todas maneras, si la idea de "resolver" es el criterio para diferenciar a filósofos no analíticos de filósofos analíticos la cosa no es clara si se supone que hay filósofos que se asumen como analíticos por realizar "análisis conceptual”, aunque su idea del análisis y los conceptos los conecte con una concepción esencialista del lenguaje y los conceptos.

${ }^{89}$ Digo "algunos" pero habría autores más pesimistas como Unamuno que admitirían que todo conflicto de valores implica elección trágica desde que “... sólo vivimos de contradicciones, y por ellas; como que la vida es tragedia, y la tragedia es perpetua lucha, sin victoria ni esperanza de ella; es contradicción”. Ver De Unamuno, Miguel: Del Sentimiento Trágico de la Vida, Compilación y prólogo de Nerio Tello, Errepar, Bs As, 2000, p. 26.

${ }^{90}$ En "Conflictos trágicos, ponderación racional y respuesta correcta. En torno a algunas ideas de Robert Alexy y Ronald Dworkin”, actualmente en elaboración, desarrollo un análisis de la cuestión más pormenorizado.
} 
correctas $^{91}$. Además, cree que los empates entre principios son situaciones "raras" en sistemas jurídicos evolucionados ${ }^{92}$, que la inconmensurabilidad y vaguedad son fenómenos igualmente raros solo admisibles en casos extremos de indeterminación ${ }^{93}$ y que los choques trágicos entre valores pueden ser eliminados o disminuidos por una concepción interpretativista que ponga en armonía a los valores ${ }^{94}$.

En cierta forma, una posición como la de Dworkin, tiene un parecido de familia con una posición como la de Richard Hare ${ }^{95}$. Ello es así porque, aunque Hare admite limitaciones para la racionalidad práctica, cree que en un nivel que él llama "crítico", los dilemas morales pueden ser resueltos. En rigor, como ya señalé antes, para Hare los dilemas morales genuinos son "productos de ficción". ${ }^{96}$

Recuérdese que el nivel "crítico" en que piensa Hare es una combinación de universalismo kantiano y cálculo utilitario ${ }^{97}$. El universalismo kantiano conduce concretamente a considerar "imparcialmente" todos los intereses de los afectados ${ }^{98}$, mientras que el cálculo utilitario permite maximizar un resultado.

Es posible que el nivel crítico de Hare pudiera eliminar muchos conflictos trágicos pero ello no hablaría en contra de la posibilidad de conflictos trágicos genuinos sino que, más bien, afirmaría que los casos tratados en el nivel de Hare eran aparentes.

${ }^{91}$ Por ejemplo en Dworkin, Ronald: “¿Pueden ser controvertibles los derechos?”, en Los Derechos en Serio, Traducción de Marta Guastavino, Planeta Agostini, Barcelona, 1993, Capítulo 13.

${ }^{92}$ Ver por ejemplo la réplica de Ronald Dworkin a "Munzer y la tesis de la única respuesta correcta”, en "Réplica a los críticos”, Los Derechos en Serio, op. cit., p. 457.

${ }^{93}$ Ver por ejemplo Dworkin, Ronald: “Is There No Really Rigtht Answer in Hard Cases?”, en A Matter of Principle, Harvard University Press, Cambridge, Massachusetts, 1985, p. 144.

${ }^{94}$ Dworkin, Ronald: "Do Liberal Values Conflict?”, en The Legacy of Isaiah Berlin, op. cit., p. 89. Ver también de la misma obra The Legacy of Isaiah Berlin, en "Discussion”, sugerencias de Dworkin sobre esto en p. 126.

${ }^{95}$ Además, hay parecidos entre el "arcángel” de Hare y el "Hércules” de Dworkin que aquí no puedo tratar. Ver Hare, Richard: “Cómo resolver los problemas morales racionalmente”, en Racionalidad. Ensayos sobre la racionalidad en ética y política, ciencia y tecnología, op. cit., p. 70 .

${ }^{96}$ Hare, Richard: “Cómo resolver los problemas morales racionalmente”, en Racionalidad. Ensayos sobre la racionalidad en ética y política, ciencia y tecnología,op. cit., p. 69.

${ }^{97}$ Hare, Richard: “Cómo resolver los problemas morales racionalmente”, en Racionalidad. Ensayos sobre la racionalidad en ética y política, ciencia y tecnología,op. cit., pp. 68-69.

${ }^{98}$ Hare, Richard: “Cómo resolver los problemas morales racionalmente”, en Racionalidad. Ensayos sobre la racionalidad en ética y política, ciencia y tecnología,op. cit., pp.67-68. 
Porque, ¿podría aplicarse la universalización kantiana en un caso como el de la "elección” de Sofía? ${ }^{99}$

Sofía es una mujer judía que está alojada coactivamente en un campo de concentración nazi junto a sus dos hijos. Uno de los guardas nazis le “ordena” matar a uno de sus hijos ${ }^{100}$, si no hiciera esto, él mismo se encargará de matar a ambos. De una misma orden ${ }^{101}$ surgen dos acciones independientes. Este tipo de versión de conflicto trágico es conocida en la literatura como expresiva de casos "simétricos". ${ }^{102}$ El caso es trágico en cuanto hay dos acciones que llevan la exigencia de hacer algo que es a todas luces incorrecto. La tragedia es total si se admite que éste es un caso emblemático de conflicto genuino en cuanto no hay posibilidad de resolución alguna, desde que sería problemático pensar que sea posible universalizar todos los intereses en juego, los de Sofía, los de sus dos hijos y los del guarda nazi.

Si el caso de Sofía no es "puro producto de ficción”, como arguye Hare, la tesis de los límites de la racionalidad sigue incólume. Pero, ¿cuál sería la consecuencia de esta tesis? ¿Irremediablemente solo quedaría un acto de “elección”? Y, esta elección, ¿siempre lleva a un decisionismo no racional?

Uno podría pensar que ésta es la situación en un caso como el del estudiante francés que Sartre comenta en El Existencialismo es un Humanismo.

La respuesta de Sartre al estudiante, en el sentido de que éste no tiene más remedio que "elegir” y “comprometerse” con las consecuencias de su decisión, es generalmente vista, sin mayor discusión, como expresiva del

\footnotetext{
${ }^{99}$ Citado por McConnell, Terrance: “Moral Dilemmas”, op. cit., p. 3.

${ }^{100}$ Uso deliberadamente la expresión "le ordena” en boca del guardia nazi y eliminé la expresión “dar una orden” para sugerir, al igual que Hart, que la distinción revela que en un caso hay autoridad o pretensión de autoridad y no necesariamente en el otro. Si hubiera autoridad en el guarda nazi sus razones serían “excluyentes” para seguir el vocabulario que Joseph Raz ha hecho tan popular. Ver Raz, Joseph: Razón Práctica y Normas, Traducción de Juan Ruiz Manero, Centro de Estudios Constitucionales, Madrid, 1991, especialmente pp. 53-54. Como se sabe, Raz distingue dos hipótesis de razones excluyentes. Una generada por el propio agente que tiene que decidir, el cual considera que, debido a una incapacidad temporal para decidir algo problemático o que exige mucho discernimiento intelectual para formarse un juicio ponderado, delega la decisión en otro. Las razones excluyentes típicas, sin embargo, son para Raz aquellas suministradas por una autoridad normativa. No voy a contar aquí las tesis que definen la idea de autoridad en Raz ni si ellas son un conjunto fuerte en la disputa con el anarquismo. Lo que quiero señalar es otra cosa: que si hubiera "autoridad” en el nazi (porque por ejemplo no ha fracasado la tesis de la "justificación normal, lo que muy difícilmente podría aceptarse) la idea de un conflicto práctico genuino podría diluirse, pues habría una razón excluyente, apoyada en una autoridad pretensa o efectiva, que eliminaría una de las acciones en juego. Ni siquiera el agente, en este caso Sofía, tendría que operar balance de razones alguno. Pero decir que hay tal cosa podría ser fruto de un ejercicio intelectual extravagante.

${ }^{101}$ Esto muestra que un dilema no tiene por qué ser representativo del conflicto entre dos principios, bien puede surgir de uno.

${ }^{102}$ McConnell, Terrance:”Moral Dilemmas”, op. cit., p. 3.
} 
"decisionismo" y el "particularismo" moral. En el ejemplo, Sartre sostiene que hay morales en conflicto pero que no hay ninguna moral que, para el caso, muestre prevalencia «a priori”. Pero, ¿de qué depende la elección de los valores en pugna? Sartre contesta que de una decisión. Su argumento es que "en el fondo, lo que importa es el sentimiento; el estudiante debería elegir lo que lo empuja verdaderamente en cierta dirección”.

Cuando se dice que Sartre es "decisionista" parece darse por sentado que es la "decisión” la razón última de la elección. Pero en estricto rigor es el sentimiento ${ }^{103}$. Pero no se trata de cualquier sentimiento sino de uno que "tira más" en "cierta dirección" (o unirse a las fuertes aliadas o cuidar a la madre).

Esto pareciera hablar a favor de que la intuición o el sentimiento podría llevar a elegir en el sentido correcto. Pero esto no es evidente, pues, se pregunta Sartre, cómo puede determinarse el "valor" de un sentimiento.

Sartre cree que hay aquí un "círculo vicioso" pues para determinar el valor (o peso) del sentimiento no hay más remedio que ejecutar el acto al que la dirección del sentimiento ha conducido. ${ }^{104}$

Una manera de decidir esto, según Sartre, podría ser invocando razones en términos "consecuencialistas". Por ejemplo, si pudiera mostrarse que la elección de un valor hace más "eficaz” una decisión, entonces, se dispondría de un criterio para escoger alguno de los valores. ${ }^{105}$ Pero esto no es fácil de mostrar si lo que tiene prioridad es el "sentimiento" y no un "cálculo de probabilidades."

¿Qué es lo que queda después de todo? Lo que Sartre denomina la "moral del compromiso". Tomar una decisión y comprometerse. Pero este "compromiso" no es baladí. Sartre sostiene que este compromiso supone

${ }^{103} \mathrm{El}$ tema de los sentimientos justificaría en sí mismo un tratamiento independiente que aquí no puedo ofrecer. ¿Cómo se puede reconstruir apropiadamente este conflicto de sentimientos? ¿Es lo mismo que un conflicto de razones? MacIntyre pone en duda esto. Para él, los personajes homéricos no se representan las cosas en términos de razones que hay que sopesar. Cuando en la Ilíada Odiseo se queda solo en el campo de batalla siente temor y se representa a sí mismo conflictuado por el temor que lo impulsa a dejar el campo de batalla y salvar su vida y la experiencia de que si hace eso violaría la areté que demanda no abandonar el campo. Según MacIntyre no hay aquí un conflicto de razones. Odiseo convoca para sí a la areté como una manera de traer un sentimiento -educado moralmente- para que conjure o discipline los peligros de los sentimientos "bajos" como el miedo. Ver esto en términos de conflictos de razones sería practicar una "mala traducción”, algo que, según MacIntyre los filósofos analíticos suelen hacer con frecuencia por su desapego de los contextos históricos de cada tradición filosófica. Por ejemplo en MacIntyre, Alasdair: Justicia y Racionalidad, op. cit., pp. 35-37.

${ }^{104}$ Sartre, Jean Paul: El Existencialismo es un Humanismo, op. cit., p. 23.

${ }^{105}$ Sartre, Jean Paul: El Existencialismo es un Humanismo, op. cit.,p. 21. 
hacerse "responsable" de lo que se decide ${ }^{106}$ en el sentido de que la elección del agente compromete a toda la humanidad. ${ }^{107}$

En cualquier caso, y aun si mi interpretación de Sartre es superficial, creo que ella pone en evidencia por qué la cuestión de los límites de la racionalidad y sus consecuencias están todavía lejos de ser claras tanto en el dominio general de la filosofía práctica como en el dominio particular del derecho.

Pero una investigación sistemática orientada a discutir con detalle cuán compulsivos puedan ser los límites de la racionalidad para el derecho, vía los conflictos trágicos, es una tarea que prometo desarrollar en un futuro trabajo.

${ }^{106}$ En efecto, dice Sartre "no hay ninguno de nuestros actos que al crear al hombre que queremos ser, no cree al mismo tiempo una imagen del hombre tal como consideramos que debe ser”. Aunque pueda parecer extraña mi afirmación, creo que hay ciertos ingredientes con aire de familia kantianos en Sartre. Pues él dice que: "elegir ser esto o aquello, es afirmar al mismo tiempo el valor de lo que elegimos, porque nunca podemos elegir mal; lo que elegimos es siempre el bien, y nada puede ser bueno para nosotros sin serlo para todos; si, por otra parte, la existencia precede a la esencia y nosotros quisiéramos existir al mismo tiempo que moldeamos nuestra imagen, esta imagen es valedera para todos y para nuestra época entera; así, nuestra responsabilidad es mucho mayor de lo que podríamos suponer, porque compromete a la humanidad entera; si, por ejemplo, soy obrero, elijo adherirme a un sindicato cristiano quiero indicar que la resignación es en el fondo la solución que conviene al hombre, que el reino del hombre no está en la tierra, no comprometo solo mi caso: quiero ser un resignado para todos”. Hasta qué punto la idea de Sartre de que no hay una moral de validez general, de que las decisiones son para el caso, se compatibiliza con su idea de que al elegir en un caso comprometo a la humanidad entera, es algo que dejo abierto para reflexión.

${ }^{107}$ Ver Sartre, Jean Paul: El Existencialismo es un Humanismo, op. cit., p. 14. 